Authors have nothing to disclose with regard to commercial support.

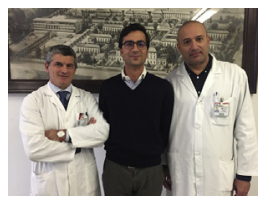

\section{STRAIGHT DEEP HYPOTHERMIC CIRCULATORY ARREST: SHOULD WE DEFINITIVELY GIVE UP OR SHOULD WE KEEP ON?}

\section{To the Editor:}

In their retrospective monocentric study, Damberg and colleagues ${ }^{1}$ highlight their experience with the use of deep hypothermic circulatory arrest (DHCA) as a cerebral protection strategy during aortic arch operations. The authors analyzed data on 613 consecutive patients between 2003 and 2015 . The majority of patients $(\mathrm{n}=529 ; 86.3 \%)$ underwent elective surgery, and $474(77.3 \%)$ underwent hemiarch replacement. Total aortic arch replacement was performed in 125 patients $(20.4 \%)$. The authors reported a stroke incidence of $2 \%(n=12)$, whereas minor cerebral damage, such as seizure and temporary neurologic deficit, were observed in $1 \%(n=6)$ and $5.1 \%(n=31)$, respectively. Damberg and colleagues concluded that stroke was one of the independent variables that negatively affect late survival, whereas circulatory arrest time was a nonsignificant variable associated with both early and late survival.

The authors should be congratulated for their excellent results in this very challenging clinical scenario; however, their impressive data still merit some comments. To the best of our knowledge, randomized control trials comparing straight DHCA with moderate hypothermic circulatory arrest and cerebral perfusion $(\mathrm{CP})$ are missing; most of the data come from retrospective trials.

On reading this article, the underlying problem remains the choice of neurologic protection strategy to be used in both urgent and elective operations. Unfortunately, there is no consensus on what might be the best strategy to follow. Damberg and colleagues repeatedly pointed out the very low stroke rate; however, the majority of patients $(85.5 \%)$ had a DHCA duration $<40$ minutes, which is considered a safe duration at a core temperature of $\leq 20^{\circ} \mathrm{C}$. This time is useful for an hemiarch procedure. But when a TAA

\footnotetext{
The Editor welcomes submissions for possible publication in the Letters to the Editor section that consist of commentary on an article published in the Journal or other relevant issues. Authors should: • Include no more than 500 words of text, three authors, and five references. $\bullet$ Type with double-spacing. $\bullet$ See http://jtcs.ctsnetjournals.org/ misc/ifora.shtml for detailed submission instructions. • Submit the letter electronically via jtcvs.editorialmanager.com. Letters commenting on an article published in the JTCVS will be considered if they are received within 6 weeks of the time the article was published. Authors of the article being commented on will be given an opportunity of offer a timely response ( 2 weeks) to the letter. Authors of letters will be notified that the letter has been received. Unpublished letters cannot be returned.
}

replacement is planned, the likelihood that circulatory arrest time exceeds 40 minutes is highly probable. That said, in a recent analysis of 12,521 patients from the Society of Thoracic Surgeons Adult Cardiac Surgery Database, ${ }^{2}$ 7163 patients $(57.2 \%)$ underwent surgery under DHCA, 3083 of whom $(43 \%)$ without any form of CP. DHCA without $\mathrm{CP}$ was associated with a significantly higher risk of stroke compared with a mild hypothermia and CP strategy (odds ratio, 1.6). These data are in contrast to those reported in a recent survey of 144 European center in which DHCA was limited only to $6 \%$ of centers in acute presentation and only $2 \%$ in elective status. ${ }^{3}$ Moreover, two-thirds of centers prefer a core temperature between $22^{\circ} \mathrm{C}$ and $26^{\circ} \mathrm{C}$, and the other third still use colder temperatures. Unfortunately, this survey did not report any data on neurologic outcomes according to the different strategies used.

We strongly agree that the excellent neurologic outcomes reported by Damberg and colleagues demonstrate that straight DHCA remains a safe strategy, but only for "simple and quick" aortic arch surgery. Over the last 2 decades, the use of various techniques of "complex and long" aortic arch surgery, such as frozen elephant trunk, has expanded worldwide, surgical strategies involving moderate hypothermic circulatory arrest and CP need to be further encouraged and improved to avoid "going to dinosaurs," as Dr Kouchoukos gracefully wrote. ${ }^{4}$

Francesco Formica, $M D^{a}$ Stefano D'Alessandro, FECTS, MD Luigi Amerigo Messina, $M D^{b}$

${ }^{a}$ Cardiac Surgery Unit

Department of Medicine and Surgery

San Gerardo Hospital University of Milano-Bicocca

Monza, Italy

${ }^{b}$ Statistics and Quality Health Service

San Gerardo Hospital Monza, Italy

\section{References}

1. Damberg A, Carino D, Charilaou P, Peterss S, Tranquilli M, Ziganshin BA, et al Favorable late survival after aortic surgery under straight deep hypothermic circulatory arrest. J Thorac Cardiovasc Surg. 2017;154:1831-9.

2. Englum BR, He X, Gulack BC, Ganapathi AM, Mathew JP, Brennan JM, et al Hypothermia and cerebral protection strategies in aortic arch surgery: a comparative effectiveness analysis from the STS Adult Cardiac Surgery Database. Eur J Cardiothorac Surg. 2017;52:492-8.

3. De Paulis R, Czerny M, Weltert L, Bavaria J, Borger MA, Carrel TP, et al. Current trends in cannulation and neuroprotection during surgery of the aortic arch in Europe. Eur J Cardiothorac Surg. 2015;47:917-23.

4. Kouchoukos NT. Straight deep hypothermic circulatory arrest for aortic arch surgery: going the way of the dinosaurs? J Thorac Cardiovasc Surg. 2017;154: 1840-1.

https://doi.org/10.1016/j.jtcvs.2017.12.047 